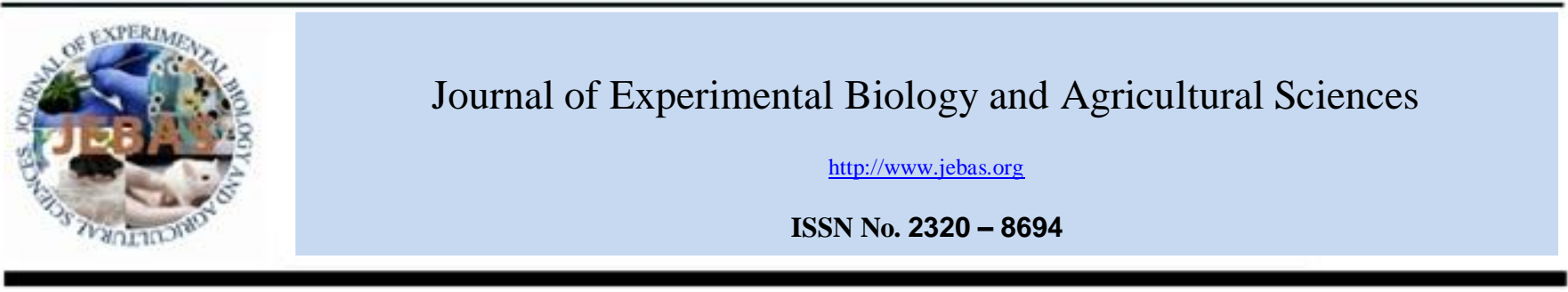

\title{
PATTERNS OF NATURAL DEGRADATION OF CYPERMETHRIN IN TOMATO FRUITS, WATER AND SOIL UNDER THE DESERT ENVIRONMENT OF OGLA OASIS CYRENAICA - LIBYA
}

\author{
Abdelkrim Amer ${ }^{1, *}$, Ifdial Omer EL-Awami ${ }^{1}$, Fathelrahman I Elsiddig ${ }^{1}$, Mahmud Aessa ${ }^{2}$ and Salah A \\ Albanqeeyah $^{3}$
}

${ }^{1}$ Plant Protection Department-Faculty of Agriculture-Omar AlmokhtarUniversity, P. O. Box 919 Al-Beida, Libya.

${ }^{2}$ Faculty of Agriculture- Ain Shams University, Cairo, Egypt.

${ }^{3}$ Higher Institute of Agricultural Techniques, El-Awelia, Al-Marj, Libya.

Received - August 10, 2015; Revision - September 02, 2015; Accepted - October 16, 2015

Available Online - October 20, 2015

DOI: http://dx.doi.org/10.18006/2015.3(5).458.463

\begin{abstract}
KEYWORDS
Cypermethrin

Degradation

Tomato

Soil

Libya

GC-ECD

Desert

ABSTRACT

Degradation line of cypermethrin were studied in different samples of tomato fruits, water, and soil from ogla oasis in the desert environment of Cyrenaica, -Libya. The targeted insecticide was applied to the tomato crop, water, and soil of the studied area with the recommended dose. Representative samples from all three subjects were taken daily which started from the first day of treatment to the $20^{\text {th }}$ days of experimentation. Extraction and cleanup were conducted on the $20^{\text {th }}$ days and finely detection of the residues was measured by using Gas chromatography (GC-ECD) instrument. Results of the study revealed $0.06,1.06$, and $2.44 \mathrm{ppm}$ insecticide concentration on the first sampling date from tomato fruits, water, and soil respectively. However after one week 33, 56 and $65 \%$ reduction in insecticide concentration was reported in tomato fruits, water and soil respectively. After 2 weeks the reduction percentage was reported $66 \%, 88 \%$, and $93 \%$ chronologically, and the degradation exert $91 \%, 97 \%$, and $99.1 \%$ in the same order at the last sampling date. Results concluded that the trends of cypermethrin degradation were fluctuating and slow in tomato fruits while in water and soil it appears regular. However the degradation in soil was the fastest.
\end{abstract}

* Corresponding author

E-mail: dr.abdelkrimamer@gmail.com (Abdelkrim Amer)

Peer review under responsibility of Journal of Experimental Biology and Agricultural Sciences.

Production and Hosting by Horizon Publisher (www.myvision.webs.com/horizon.html)

All rights reserved.
All the article published by (Journal of Experimental Biology and Agricultural Sciences) / CC BY-NC 4.0

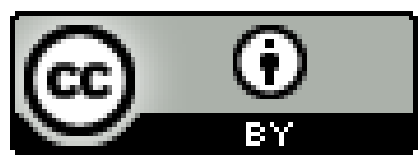




\section{Introduction}

Pesticides were extensively used at various stage of agricultural production to control pest and diseases (Menezes et al., 2006). Concerns about the excessive use of pesticides and its residues were raised more than fifty years ago. Pesticides residues are associated with many health problems; it became more serious in case of fresh vegetables and fruits (Jergentz et al., 2005). Many efforts deed to reduce the residues of these insecticides in the food stuff through legislation of laws at locally or internationally levels (Dogheim et al., 2001). The levels of pesticide residues are monitored at the maximum residue limits (MRLs), which are established by each country (Torres et al., 1996; Zawiyah et al., 2007).

Cypermethrin is a synthetic pyrethroid insecticide which used at large scale in commercial agricultural production. It has neurotoxic effect on the target organisms. Various studies conducted on its natural degradation, results of these studies suggested that it naturally degraded in soil and plant materials and its exposure to sunlight, water and oxygen will accelerate its decomposition. González-Rodríguez et al. (2008) calculated cypermethrin residues in vegetables and found higher concentrations of insecticide than the suggested maximum reside limit in 18 collected samples. However, Metwally et al. (1997) studied the degradation pattern of cypermethrin in tomato by using HPLC and reported $0.66 \mathrm{ppm}$ insecticides concentration on the first sampling, this concentration was reduced up to $0.28 \mathrm{ppm}$ after 120 hours. Furthermore, Al-Eed et al. (2006) conducted a study to evaluate the behavior of cypermethrin reduction in three types of water viz. distilled, mineral, and hard water and reported high cypermethrin residues from all three water types after one week, this concentration reduced up to $75 \%$ after three weeks of its application. In a different study, Roberts \& Standen (1981) measured the degradation of cypermethrin in a soil stored under laboratory condition and reported the presence of this insecticide from the sample collected from wheat growing soil after 52 weeks. Ogla oasis represents the agriculture in desert environment of Libya. This selected area is well known for its vegetable production, where cypermethrin insecticide was often used to control tomato pests. Though this study aimed to measure and monitors the natural degradation of cypermethrin insecticide in the tomato fruits, water and soil of Ogla oasis.

\section{Materials and Methods}

This study was conducted in Ogla oasis located in the south east of Libya at latitude $29^{\circ} \mathrm{N}$ and longitude $2^{\circ} \mathrm{E}, 220$ kilometers away from the Mediterranean Sea. It is characterized by the warmth winter and the higher temperature in the summer. Most of the area is cultivated by tomatoes in the winter.

\subsection{Optimizing GC Condition}

Gas Chromatography instrument (GC) with Electron Capture Detector provided with column (Thermo TR- 5MS $30 \mathrm{mx}$ $0.25 \mathrm{~mm}$ ID $\mathrm{x} \quad 0.50 \mu \mathrm{mfilm})$ was used in this study. Optimization GC conditions were carried out by standard solutions of cypermethrin. (Port temperature $280^{\circ} \mathrm{C}$; ECD temperature $300^{\circ} \mathrm{C}$; Column temperature $240{ }^{\circ} \mathrm{C}$;Carrier gasNitrogen; Flow rate $2.5 \mathrm{~mL} / \mathrm{min}$ )

\subsection{Calibration Curve}

Standards solution of cypermethrin were prepared on concentrations $(0.001-0.01 \mathrm{mg} / \mathrm{mL})$ and injected into the GC system under optimized condition. A calibration curves was obtained by regression of concentrations on standard peak areas with a regression coefficient 0.9895 , limit of detection (LOD) $0.00260 \mathrm{mg} / \mathrm{ml}$ and limit of quantification (LOQ) $0.00868 \mathrm{mg} / \mathrm{ml}$.

\subsection{The Recovery}

The recovery rate of cypermethrin were accounted by adding three standard solutions $(0.2,1.0$ and $2.0 \mathrm{mg} / \mathrm{kg})$ to tomato samples as chops in blender to homogenization. The same extraction procedures and GC condition was used for recovery studies as used for standard sample. The recovery rate reached to $85 \%$ by this method.

\subsection{The Degradation in tomato fruits}

Tomato variety Red Boll (PETO 111) produced by Peto seed Company was grown in one hector study area plot in the mid of August. The planting was in lines under drip irrigation system, and the distance between lines was 1 meter while the distance between each plant was $50 \mathrm{~cm}$. Cyperkill $25^{\mathrm{R}}$ insecticide produced by Chemical Agripharm was used at its Emulsifiable Concentrate (EC) contains $250 \mathrm{~g} / \mathrm{L}$ cypermethrin at $20^{\circ} \mathrm{C}$. This insecticide was applied after tomato fruits ripening and then fruit samples were collected.

\subsubsection{Samples Collection}

The cultivated area was divided into 4 regions, and three representative samples of $2 \mathrm{~kg}$ were collected from each region. All these collected samples were mixed together and divided into sub-samples each weight $100 \mathrm{gm}$ to serve as 3 replicates. The sampling process was started from the first day of insecticide application, and continued daily until reach 20 day of application.

\subsubsection{Extraction}

Extraction process was carried out according to the method described by Luke (1981), using acetonitrile solvent $100 \mathrm{~g} \backslash 100 \mathrm{ml}$, with $7 \mathrm{~g}$ anhydrous Sodium sulfate. $100 \mathrm{ml}$ of this filtrate was transferred in to a separating funnel, this was followed by addition of $100 \mathrm{ml}$ of petroleum ether and $10 \mathrm{ml}$ sodium chloride solution. This mixture shacked for two 
minutes. This process was repeated several times using petroleum ether. Evaporation was done using rotary evaporator at $32^{\circ} \mathrm{C}$, and then re-melted in $5 \mathrm{ml}$ of petroleum ether.

\subsubsection{Cleanup and detection}

The extracted samples were purified as the method described by Bolles et al.(1999), using filorassel activated column at $130^{\circ} \mathrm{C}$ temperature for 24 hours with anhydrous sodium sulfate and series of Petroleum ether solutions (with elution volume of $75 \mathrm{ml}$ ). The extraction was then evaporated in a rotary evaporator and 1 micro liter was injected in Gas.

\subsection{The Degradation in water}

Water basin of $2 \times 1 \times 0.5 \mathrm{~m}$ was settled in the same area where tomato cultivated and the basin was filled with $200 \mathrm{~L}$ water. Recommended concentration of cypermethrin insecticides $(20 \mathrm{~m} / 1000 \mathrm{~L})$ was applied in to the adjusted basin and coincides with its application in tomato field.

\subsubsection{Samples collection}

$200 \mathrm{ml}$ water sample was collected from the treated basin; this collected sample was transferred to $250 \mathrm{ml}$ bottle, covered with aluminum foil and kept in $20^{\circ} \mathrm{C}$ freezer. Same procedure was repeated daily starting from the first day of application to the $20^{\text {th }}$ days.

\subsubsection{Extraction}

Extraction was carried out by the method described by AlSarar (1996). Collected samples were extracted by using $50 \mathrm{ml}$ acetonitrile, this mixture shacked for 3 minutes. These samples were transferred to a separatory funnel and $50 \mathrm{ml}$ petroleum ether was added and shacked. This was done twice to separate the organic layer, which finally concentrated it by using a rotary evaporator.

\subsubsection{Cleanup and detection}

The extracted samples were getting through cleanup step according to the method described by Abo-El-Saad (2001). Initially, column chromatography was prepared for cleanup by adding $10 \mathrm{gm}$ of activated florisil $\left(30^{\circ} \mathrm{C}\right.$ temperature for 16 hours). Then the columnwas filled with the florisil $30 \mathrm{~cm}$ long and $25 \mathrm{ml}$ in diameter, and a layer of anhydrous sodium sulphatewas added over the florisil layer. 20-25 $\mathrm{ml}$ of petroleum ether was used to initiate the column and mixer of $40 \mathrm{ml}$ benzene/ petroleum ether was used for elution. Then the sample was injected in the same GC for detection.

\subsection{The Degradation in soil}

Four different land pieces with $16 \mathrm{~m}^{2}$ in diameter were selected in the study area where tomato crop was grown. Cypermethrin insecticide was applied to the selected areas with the same dose and in the same time where tomato field was treated.

\subsubsection{Sample collection}

Twenty soil samples were taken daily from $20 \mathrm{~cm}$ depth in each selected land pieces. These collected samples were mixed together and a representative sample $(20 \mathrm{~kg})$ was collected in a poly ethylene bag, this bag was stored at $20^{\circ} \mathrm{C}$ till the completion of study.

\subsubsection{Extraction}

The extraction process was conducted according to the method described in the Pesticide Analytical Manual(1999).A sample of $50 \mathrm{gm}$ soil was weighted from the collected soil, mixed it with $100 \mathrm{gm}$ anhydrous sodium sulphate and transferred to a chromatographic column $(40 \mathrm{~cm}$ long and 2.2 in diameter), which then eluted with $250 \mathrm{ml}$ of acetone-hexane mixture in 35 minutes elution time. The supernatant was concentrated by a rotary evaporator to a volume of $100 \mathrm{ml}$, and transferred to $1 \mathrm{~L}$ separation funnel. A volume of $300 \mathrm{ml}$ distilled water and $25 \mathrm{ml}$ of saturated solution of sodium chloride were added and shacked for 2 minutes to separate the organic layer. This step was done two times, but with $20 \mathrm{ml}$ of methylene chloridehexane mixture. Then the two extracted layers washed twice with $100 \mathrm{ml}$ distilled water and desiccated using anhydrous sodium sulphate to be added to the florisil column.

\subsubsection{Cleanup and detection}

Cleanup step was done according to the method mentioned in the Pesticide Analytical Manual (1999). The method used Activated florisil column with $40 \mathrm{~cm}$ length, 2.2 diameter and $10 \mathrm{~cm}$ florisil height. A Layer of anhydrous sodium sulphate was added to the column, which was then initiated using 40-50 $\mathrm{ml}$ of petroleum ether, and eluted with $50 \mathrm{ml}$ of diethyl ether/ petroleum ether mixture. Finally this elutes were concentrated in a rotary evaporator and injected in the GC instrument.

\section{Results and Discussion}

\subsection{Degradation in tomato fruits}

Results presented in Figure (1) showed the degradation pattern of cypermethrin in tomato fruits. It was characterized by a fluctuation in the degradation behavior at first and last $5^{\text {th }}$ days, mediated by a fixed period of about 10 days at which no degradation was observed. These results are in agreement with the findings of Metwally et al. (1997). These researchers reported a fluctuation between $0.66,0.7$ and $0.55 \mathrm{ppm}$. Results of the same figure also represented that the initial concentration in tomato fruits $(0.06 \mathrm{ppm})$ was less than the Maximum Residue Limit (MRL) recommended by Codex (1996). This was agreed with the result reported by Zawiyah et al. (2007); those were calculated the cypermethrin residues in vegetables samples especially in tomato and reported its concentration less than $0.47 \mathrm{ppm}$ and it was less than the MRL. 


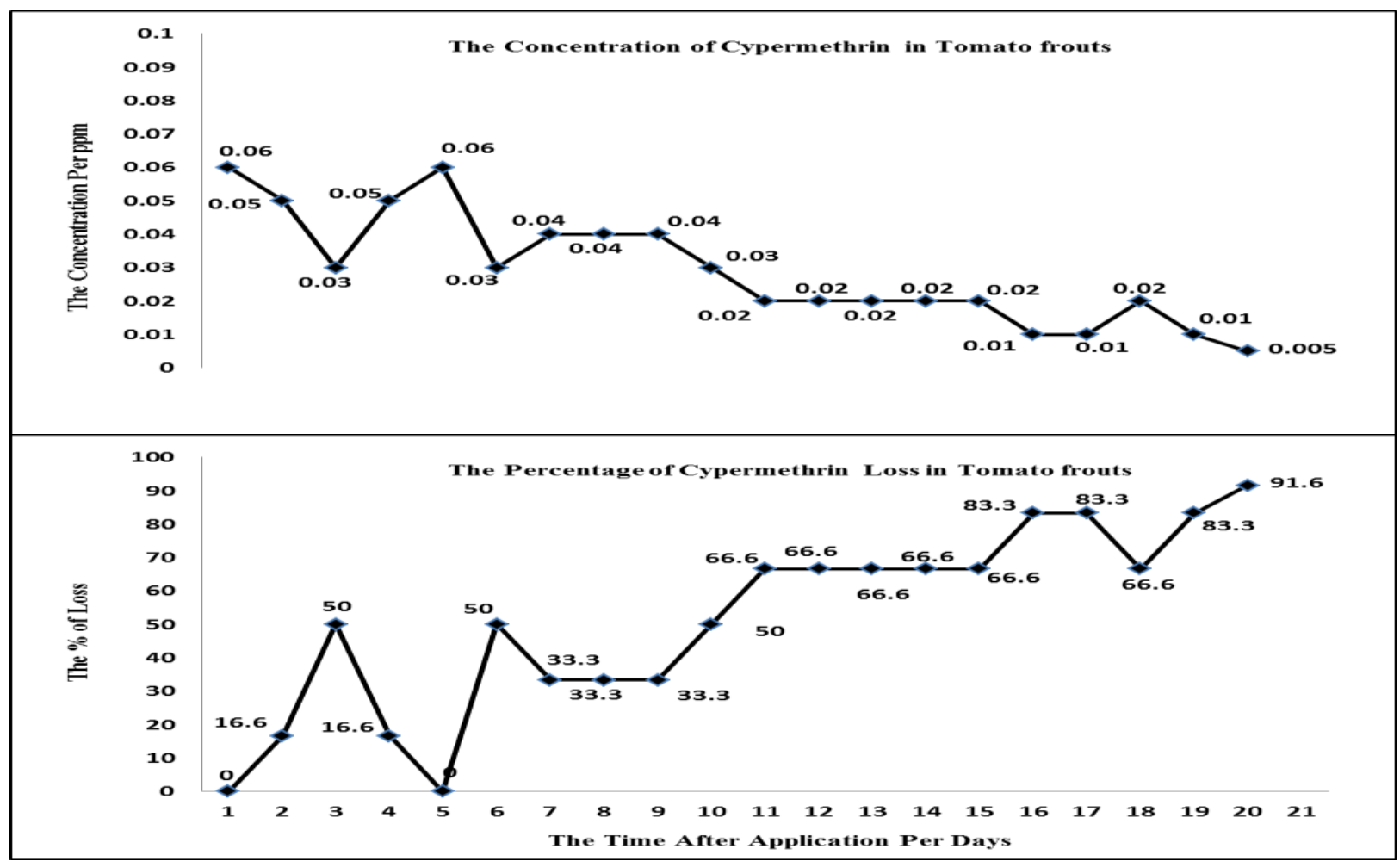

Figure 1 Concentration of cypermethrin and its reduction percentages in tomato fruits.

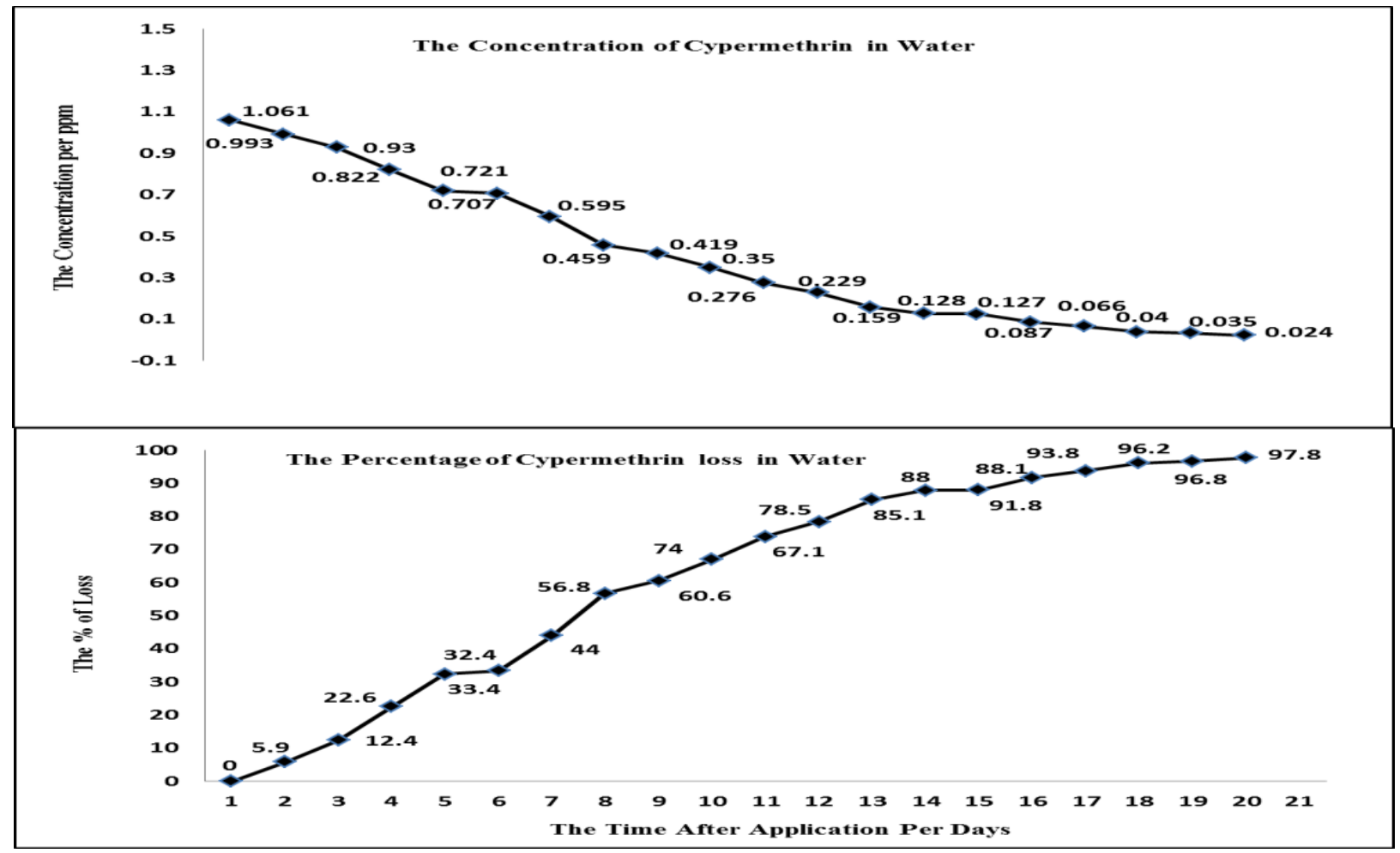

Figure 2 Concentration of cypermethrin and its reductionpercentages in water. 
3.2 Degradation in water

Results presented by figure 2, revealed the degradation pattern of cypermethrin in water. It occurred in descending manner which started from the first day depicted $0.99 \mathrm{ppm}$ with $5.9 \%$ losses and degrade up to $0.24 \mathrm{ppm}$ on the last sampling date, with losses of approximately $97.8 \%$. These results are superior to the results obtained by Al-Eed et al. (2006), degradation percentage in hard water was calculated as $85 \%$ after two weeks from cypermethrin application, whilein the present study it was $88.1 \%$ after the same period of time.

\subsection{Degradation in soil}

Results presented in Figure 3 revealed the general trend of cypermethrin degradation in soil of the study area. Regular and fast rate degradation was reported in the cypermethrin and the degradation percentage reached $30.3 \%$ after the second day of application (1.7 ppm).

Moreover this reduction reached to $55.2 \%(1.09 \mathrm{ppm})$ and $99.1 \%(0.02 \mathrm{ppm})$ on third and last day of sampling. These results agreed with the report of WHO (1989) where study pointed out the rapid degradation of cypermethrin under natural conditions at under balanced $\mathrm{pH}$.
3.4 Comparison of cypermethrin degradation in the three materials

Results of this study concluded that the initial concentrations of cypermethrin residues measured in the three studied materials were in a descending manner starting from soil $(2.44 \mathrm{ppm})$, water $(1.06 \mathrm{ppm})$, and tomato fruits $(0.06 \mathrm{ppm})$. The general degradation behavior in soil and water could be described as regular, which could be attributed to the presence of organic matter combined with soil microorganisms. While in tomato the pattern appeared as an irregular and slower than both counterparts. Results also demonstrated that the degradation percentage on the last sampling date reached up to $99.1 \%, 97 \%$ and $91.6 \%$ in soil, water, and tomato fruits respectively. This confirmed with the initial degradation behavior in the three materials. Fortunately the levels of cypermethrin residues in the three tested materials were reported below than the recommended MRL. However, that not allow to consumption the products without detect thecypermethrin levels in this products. Moreover, the degradation of this chemical in the desert environment like Ogla oasis maybe don't repeat at the same pattern in the different environments, if we concern the hard conditions in desert (high temperature; dryness; concentrate of sunlight) that may help to increase the degradation of cypermethrin more than other soft environments.

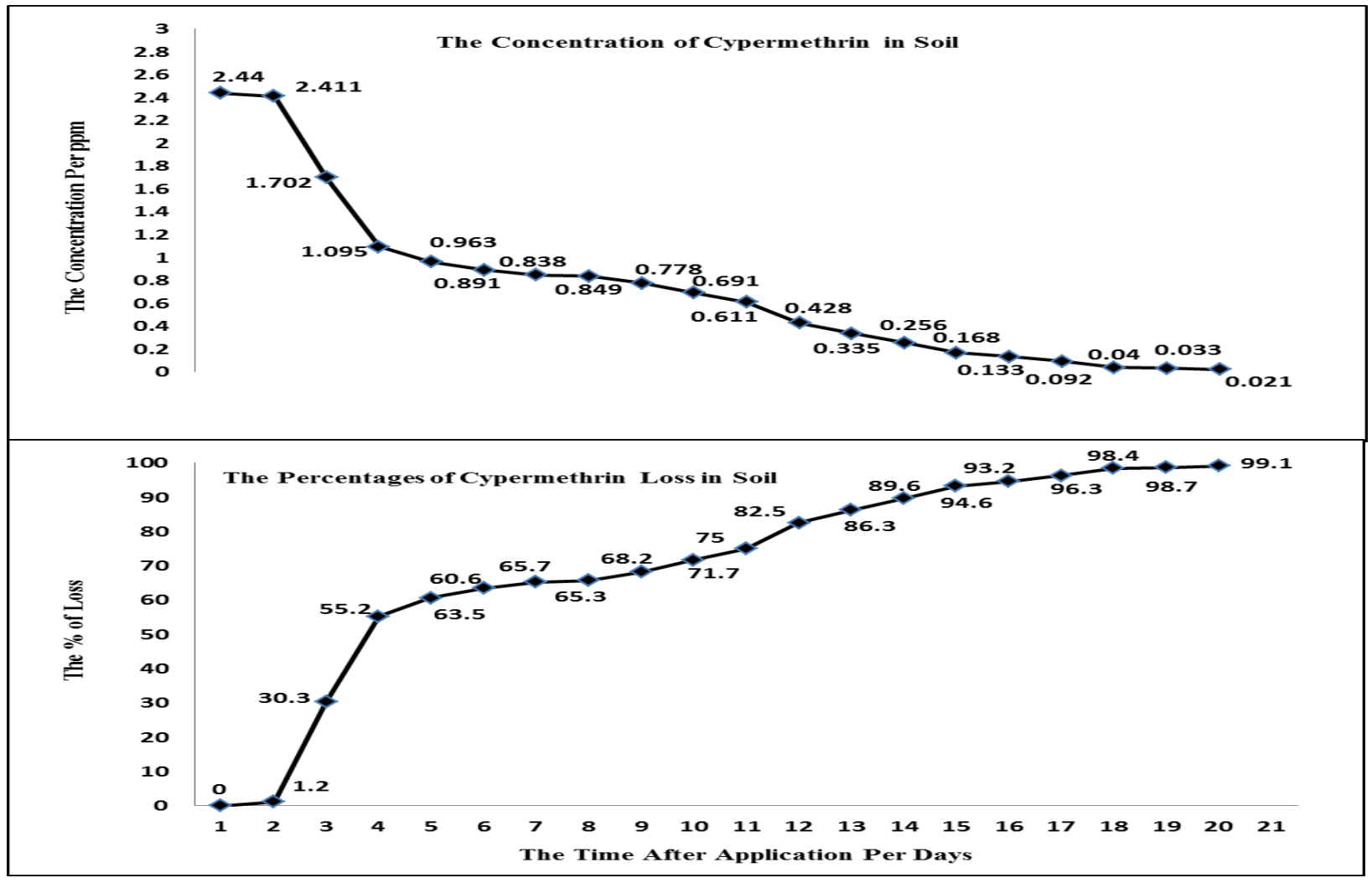

Figure 3 Concentration of cypermethrin and its reduction percentagesin soil 


\section{Conflict of interest}

Authors would hereby like to declare that there is no conflict of interests that could possibly arise.

\section{References}

Abo-El-Saad M (2001) Detection and elimination of certain insecticide residues in cucumber fruits. Alexandria Journal of Pharmaceutical Sciences 15:115.

Al-Eed MA, Abo-El-Saad M, Al-Faiyz Y (2006) Residues and Decay of Some Insecticides in Different Types of Water. Journal of Applied Sciences 6: 1833-1837. DOI: 10.3923/jas.2006.1833.1837

Al-sarar AS (1996) Residual of some insecticides on cucumber and tomatoes grown in greenhouse and their toxicological effects on male albino mice. M. Sc. Thesis submitted to the College of Agricultural Science, King Saud University, KSA Pp. 119.

Bolles HG, Dixon-White HE, Peterson RK, Tomerlin JR, Day EW Jr, Oliver GR (1999) U.S. market basket study to determine residues of the insecticide chlorpyrifos. Journal of Agricultural and Food Chemistry 47 : 1817-1822. doi: 10.1021/jf980962d.

Codex A (1996) Pesticide residues in food- Maximum Residue Limits. Volume 2B.Second edition, FAO/WHO publication.

Dogheim SM, Gad Alla SA, El-MarsafyAM (2001) Monitoring of pesticide residues in Egyptian fruits and vegetables during 1996. Journal of AOAC International 84: 519-531.

González-Rodríguez RM, Rial-Otero R, Cancho-Grande B, Simal-Gándara J (2008) Determination of 23 pesticide residues in leafy vegetables using gas chromatography-ion trap mass spectrometry and analyte protectants. Journal of Chromatography A 1196-1197: 100-109. doi:10.1016/j.chroma.2008.02.087.
Jergentza S, Mugnib H, Bonettob C, Schulzc R (2005) Assessment of insecticide contamination in runoff and stream water of small agricultural streams in the main soybean area of Argentina. Chemosphere 61: 817-826. doi:10.1016/j.chemosphere.2005.04.036

Luke MA (1981) Extraction with acetone, liquid partitioning with petroleum ether methylene chloride. Journal of Association of Analytical Chemistry 64: 1187-1195.

Menezes Filho A, Navickiene S, Dórea HS (2006) Development of MSPD method for the determination of pesticide residues in tomato by GC-MS. Journal of the Brazilian Chemical Society 17:874-879.

Metwally MES, Osmanb MS, Al-Rushaid R (1997) A highperformance liquid chromatographic method for the determination of cypermethrin in vegetables and its application to kinetic studies after greenhouse treatment. Food Chemistry 59: 283-290. doi:10.1016/S0308-8146(96)00030-1.

Pesticide Analytical Manual (1999) U.S. Food and Drug Administration 10903 New Hampshire Avenue Silver Spring, MD 20993available on http://www.fda.gov/Food/FoodScienceResearch/LaboratoryMe thods/ucm111455.htm access on 26 May, 2015.

Roberts TR, Standen ME (1981) Further studies of the degradation of the pyrethroid insecticide cypermethrin in soils. Pesticide Science 12: 285-296. doi: 10.1002/ps.2780120306.

Torres CM, Picó Y, Mañes J (1996) Determination of pesticide residues in fruit and vegetables. Journal of Chromatography A 754:301-331. doi:10.1016/S0021-9673(96)00407-4.

World Health Organization ( 1989) Environmental Health Criteria 82: cypermethrin. InternationalProgram on chemical safety (IPCS), Geneva.

Zawiyaha S, CheManb YB, Nazimahc SAH, Chind CK, Tsukamotod I, Hamanyzaa AH, Norhaizana I (2007) Determination of organochlorine and pyrethroid pesticides in fruit and vegetables using SAX/PSA clean-up column. Food Chemistry 102 : 98-103. doi:10.1016/j.foodchem.2006.05.003. 